Journal of Professional \& Applied Psychology

Original Article

\title{
Impact of Sexual Jealousy on Partner Infidelity among University Students: Gender as Moderator
}

\author{
Dr. Muhammad Saleem ${ }^{1}$, Amna Nazeer ${ }^{2}$, and Areeha Khan Durrani ${ }^{3}$
}

\begin{abstract}
This research was aimed to examine the moderating role of gender on the impact of sexual jealousy on partner infidelity among university students. For the purpose, a sample of 352 students were recruited through simple random sampling technique from four cities (Bahawalpur, Multan, Lahore, Rawalpindi) of Punjab, Pakistan. Respondents were given two questionnaires; Interpersonal Jealousy Scale and Infidelity Questionnaire. After data collection, results were analysed through SmartPLS (3.0) for moderation model. The results showed that sexual jealousy had significant positive impact showing 59\% variance on partner infidelity, whereas, gender was found to be a significant moderator between sexual jealousy and partner infidelity $\left(\mathrm{R}^{2}=0.594, \mathrm{t}=2.403, p<.01\right)$. The results of this research are discussed in detail with limitations and future suggestions for the future researches related to impact of sexual jealousy on partner infidelity.
\end{abstract}

Keywords: Sexual jealousy; Partner infidelity; University students; Gender; Punjab.

Received: 4 May 2020; Revised Received:

23 May, 2020; Accepted: 23 June 2020

${ }^{1}$ Associate Professor, Dept. of Applied

Psychology, The Islamia University of

Bahawalpur.

${ }^{2}$ MPhil Scholar, Dept. of Applied

Psychology, The Islamia University of

Bahawalpur.

${ }^{3} \mathrm{PhD}$ Scholar, Dept. of Applied

Psychology, The Islamia University of

Bahawalpur.

Corresponding Author Email:

chsaleem_1@hotmail.com

\section{Introduction}

Sexual jealousy is a basic emotion present in every individual which is not usually depicted through the facial features. It is considered as crucial in solving the survival problem as it is evolved through the various stages of human mating. However, there are few adaptive functions considered as similar to men and women, for example, the tendency of averting the potential partners and discouraging involvement of any other individual in the relationship (Buss, 2018).
Although, there are several other genderdifferentiated factors related to the men as they are considered to provide the monetary and economic benefits to the women (DelPriore et al., 2012). Several studies have been conducted for the genderdifferentiated features of jealousy. The studies show the connotation that people are relative upset about various sexual and emotional aspects of infidelity (Geary, 2010; von Hippel \& Buss, 2017), their memories regarding distress to emotional and sexual infidelity cause the physiological distress among them (Edlund \& Sagarin, 2017).

It has also been established that the rivals of same gender usually provoke the sense of jealousy within the individuals such as being superior in job as compared to the physical attractiveness causes the mate retention tactics. Due to this connotation of jealousy, the infidelity is discovered leading towards the forgiveness of breakup in the relationship (Buss, 2016; Duntley \& Buss, 2012; Sagarin et al., 2012). However, within all the hallmarks of functionality, the sexual jealousy also tends to lead towards

This article is distributed under the terms of the Creative Commons Attribution Non Commercial 4.0 License (http://www.creativecommons.org/licenses/by-nc/4.0/) which permits non-Commercial use, reproduction and distribution of the work without further permission provided the original work is attributed as specified. 
the destruction of violence, homicide or humiliation.

In the theoretical consideration, sexual jealousy is taken as basic and most important emotion (Buss, 2013). For considering the gender differentiated narratives, women often interpret male jealousy as an expression of love, they develop a sense here that this is the way of their partner showing love for them (Boyce et al., 2016). Men take sexual infidelity as most distressing in their relationships whereas females are more concerned about the emotional infidelity (Sheets \& Wolfe, 2001; Pietrzak et al., 2002).

Whereas, infidelity is termed as the extrapair involvement of individuals which would affect the existing pair and being in relationship either sexual or emotional with a third party (Valentova et al., 2020). Curiously, negative feelings are exhibited when one's partner is being involved in a sexual or emotional relationship with a rival (Aumer et al., 2014) such as jealousy, and possibly low intrasexual competition. Apart from the baseline factor, the jealousy can be triggered by several overt reasons, for example, any attractive rival is being encountered (Pollet \& Saxton, 2019).

A person experiencing the sexual jealousy and rivalry with any other person is considered as being jealous and can feel the sense of competition towards them, as their partner is being involved and doing nothing to consider the terms of breaking the relationship or understanding the fidelity norms (Donovan \& Emmers-Sommer, 2012). If we consider the basic societal patterns, in every culture, gender specific jealousy and infidelity norms are considered to lead towards extreme aggression and violence in the partners.

The social structure theory known as Theory of Gender and Power (TGP) is considered to define that gender is used basically for the evolution of power which usually creates inequity for the male and female (Connell, 1987). This theory also declares that due to double standards present in society regarding the gender and social acceptance of infidelity, it is taken as the most important concept through which individual exhibits the sexual jealousy for the partners. Studies have reported that due to social acceptance of male infidelity, women feel weak for affecting their partners so that they remain faithful and loyal in their relationships (Boyce et al., 2016; Hahm et al., 2012).

In Pakistani context, a study conducted by Chaudhary et al. (2018) on mate competition proposed that, male usually depict the cues of intra sexual jealousy and threatening infidelity while females exhibits mate-retention strategies against these cues as a defence mechanism. However, the prevalence and proportion of sexual jealousy and infidelity among the partners and its possible effects are yet to be explored.

It can be assumed that sexual jealousy and partner infidelity are most crucial and critical aspects of any relationship of the modern era and nowadays, they can be considered as the prime factor for relationship perceptions of today's Pakistani youth. But, according to the authors' best knowledge, the Pakistani literature lacks the evidences which exhibits the influence of sexual jealousy on infidelity of partner in young student population. So, in the same vein, our study is designed to assess the effect of sexual jealousy on partner infidelity with idea of capturing the interaction of genderdifferentiated relationship between both.

\section{Objectives of the Study}

The study was conducted with objectives to find out the impact of sexual jealousy on partner infidelity, and to quantify the moderating role of gender between the sexual jealousy and partner infidelity among university students.

\section{Method}

\section{Research Design and Sampling}

This study was conducted in four cities of Punjab (Bahawalpur, Multan, Lahore and Rawalpindi) following the cross-sectional 
research design. A sample of 352 university students $($ male $=177$; female $=175$ ) was drawn from public sector universities through simple random sampling technique for the collection of data. The sample size was determined by using a-priori sample size calculator through statistical software (Soper, 2019).

\section{Inclusion and Exclusion Criteria}

Only those students were included who are in relationship (asked through demographic sheet) and single partner was taken, not the couple. Any participant being single, married or divorced were excluded. Those participants were also excluded whom showed any physical or psychological disability.

\section{Instruments}

\section{Interpersonal Jealousy Scale (IJS)}

A 28-item scale was used to determine the level of sexual jealousy developed by Mathes and Severa (1981). It is a 9-point Likert type scale which indicates the feelings of respondents. The original scale has reliability of 0.86 and for the current study, the internal consistency of this scale is 0.87 .

\section{Infidelity Questionnaire (INFQ)}

This scale has 24-items based on the statements related to reasons for men/women cheat their partners in relationship (Yeniceri \& Kökdemir, 2006). The participants responded on 5-point Likert scale to indicate the importance of given reason i.e. 1 (not important at all) to 5 (very important). The reliability for the original measure and current study both was 0.83 .

\section{Procedure}

After obtaining the approval from research ethical committee to conduct this study, the authors of measurement instruments were approached for permission of using measures in the research. Further, the participants were asked to fill the consent form and demographic information sheet asking about their gender. Participants were ensured about the confidentiality of their information provided in this research. They were also informed about the research purpose and their voluntary participation in this research. The collected data were analysed through SmartPLS (3.0) for the moderation model through PLS algorithm, blindfolding and bootstrapping.

\section{Results}

\section{Table 1}

Moderating effect of Gender on Sexual Jealousy and Partner Infidelity (N=352)

\begin{tabular}{lccccccc}
\hline \multicolumn{1}{c}{ Relationship } & $\begin{array}{c}\text { Path } \\
\text { coefficient }\end{array}$ & $\mathbf{t}$ & $\boldsymbol{p}$ & $\mathbf{R}^{\mathbf{2}}$ & $\mathbf{A d}^{\mathbf{2} \mathbf{R}^{2}}$ & $\mathbf{f}^{\mathbf{2}}$ & $\mathbf{Q}^{\mathbf{2}}$ \\
\hline $\begin{array}{l}\text { Sexual Jealousy> } \\
\text { Partner Infidelity }\end{array}$ & 0.576 & $14.244^{* * *}$ & 0.000 & - & - & 0.645 & - \\
$\begin{array}{l}\text { Gender>Partner } \\
\text { Infidelity }\end{array}$ & 0.310 & $6.306^{* * *}$ & 0.048 & - & - & 0.184 & - \\
$\begin{array}{l}\text { Sexual Jealousy } \\
\text { Gender> Partner }\end{array}$ & 0.114 & $2.403^{* * *}$ & 0.017 & - & - & 0.022 & - \\
$\begin{array}{l}\text { Infidelity } \\
\text { Partner Infidelity }\end{array}$ & - & - & & & & & \\
\hline
\end{tabular}

$* * * p<.01$

Note. The Table 1 shows the significant moderating role of gender on sexual jealousy and partner infidelity ( $\mathrm{t}=2.403)$. Whereas the value of $\mathrm{R}^{2}$ coefficient $=0.594$ shows variance in partner infidelity and $\mathrm{Q}^{2}$ value $=0.172$ shows the relevance of model. 


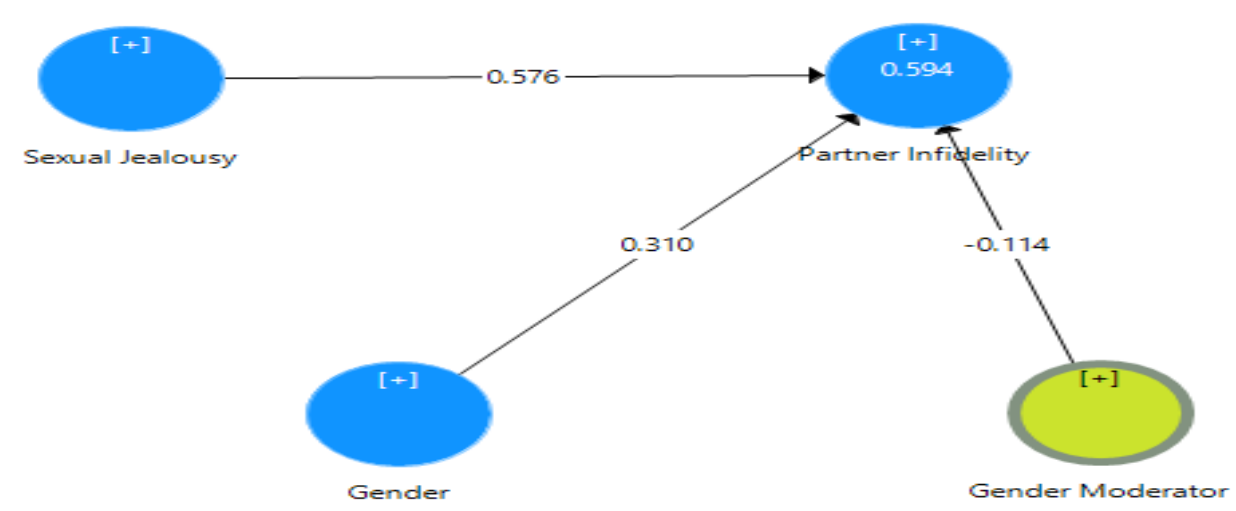

Figure 1. Structural model for gender having moderating effect on sexual jealousy and partner infidelity

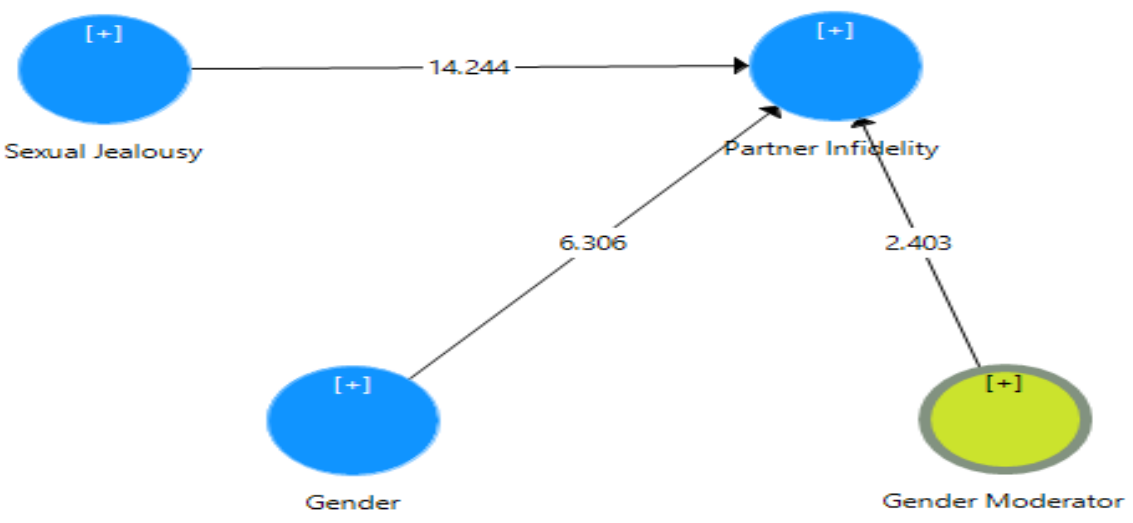

Figure 2. Significance (t-value) in structural model of gender showing moderating effect on sexual jealousy and partner infidelity through Bootstrapping 


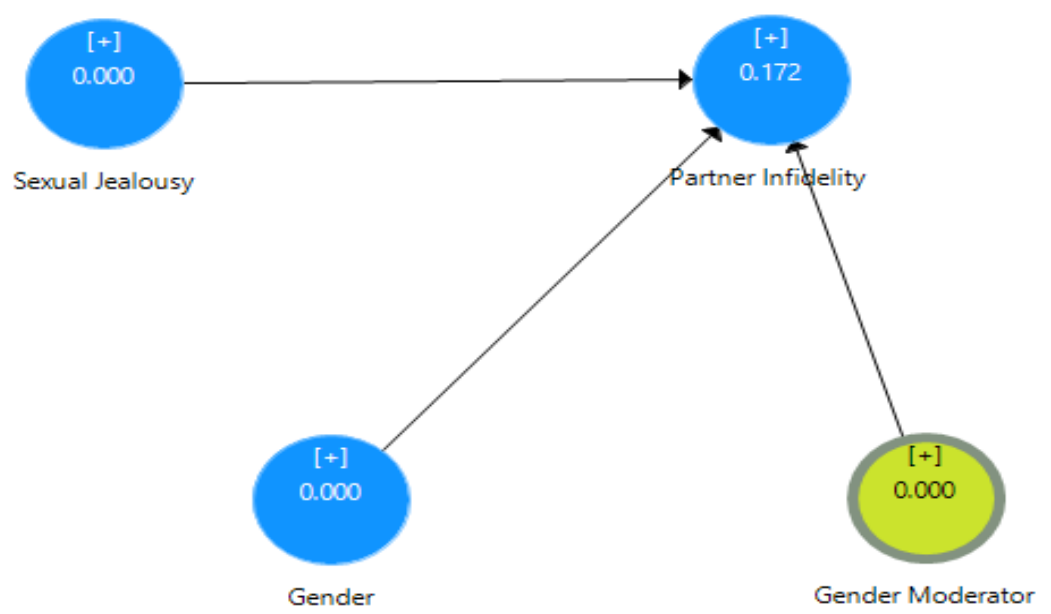

Figure 3. Value for $Q^{2}$ by blind folding in structural model of partner infidelity showing significant moderating effect of gender

\section{Discussion}

The results of present study have provided a substantial evidence for the significant positive effect of sexual jealousy on partner infidelity. The results shown in Table 1 showed 59\% variance in partner infidelity whereas gender was shown to be a significant moderator with $\mathrm{t}$-value $=2.403$ and $\mathrm{Q}^{2}=0.172$, which depicted the good relevance of model. The figures also depict the significance of moderation model. Through these findings, we can establish the strong gender-differentiated influence of sexual jealousy on infidelity. Jealousy is supposed to be a significant element in securing the relationship from the third person. It helps the individuals to restrain from getting involved in any other person for sexual or emotional needs. Studies have reported that individuals showing jealousy regarding the involvement of partners in others are also very much concerned about the infidelity, although there exists genderdifferentiated patterns for men and women. As men are more prone towards the sexual infidelity whereas females are more concerned and prone towards the emotional infidelity (Valentova et al., 2020). Recent studies have also reported that women tend to show more emotional and reactive jealousy as compared to men who have always been in sexual jealousy. However, there is tendency within the women to invest more into their partners for avoiding any kind of involvement of third party or men being in other relationships or getting attracted to other women (Bendixen et al., 2015; Fisher, 2017, Valentova et al., 2020). For considering the role of gender in sexual jealousy and infidelity of partner in adult student population, studies have theorized that the jealousy stems through various reproductive challenges which are faced by males and females. The male jealousy for their partner being unfaithful would function to reduce the risk of females being infused by the rival males whereas female jealousy functions to reduce the risk of their male partners investing the resources or getting emotionally attached with the rival females (Buss et al., 2001; Kemer et al., 2016). Further, as the study conducted in Pakistani population by Chaudhary et al. (2018) also supports the findings of our 
research that gender-differentiated factors are considered important for the mate retention strategies for causing sexual jealousy and partner infidelity among the young population. The above cited literature and inferences drawn from our results supports the study design and relationship of sexual jealousy and partner infidelity being examined in this research.

\section{Limitations and Recommendations}

The generalization of results on the whole Pakistani population cannot be claimed as the sample encompassed of the Punjab only. The gender was taken as moderator in this research, it is also expected to replicate the study for demographic differences and other covariates to arrive at the prudent findings for sexual jealousy and partner infidelity. Moreover, the sample consisted of university students only, it is also suggested to employ the research on married couples for exploring and examining the factors which leads towards sexual jealousy and partner infidelity.

\section{Conclusion}

This study concluded that there is significant positive impact of sexual jealousy on partner infidelity among the university students. This study also established that gender plays a significant moderating role for the impact of sexual jealousy on partner infidelity.

\section{Conflict of Interest}

The authors reported no conflict of interest.

\section{Source of Funding}

The authors declare no source of funding.

\section{References}

Aumer, K., Bellew, W., Ito, B., Hatfield, E., \& Heck, R. (2014). The happy green-eyed monogamist: Role of jealousy and compression in monogamous and non-traditional relationships. Electronic Journal of Human Sexuality, 17(1), 77-88.
Bendixen, M., Kennair, L. E. O., \& Buss, D. M. (2015). Jealousy: Evidence of strong sex differences using both forced choice and continuous measure paradigms.

Personality and Individual Differences, $\quad 86, \quad 212-216$. http://doi.org/10.1016/j.paid.2015. 05.035

Boyce, S., Zeledón, P., Tellez, E., \& Barrington, C. (2016). Genderspecific jealousy and infidelity norms as sources of sexual health risk and violence among young coupled Nicaraguans. American journal of public health, 106(4), 625-632. http://doi.org/10.2105/AJPH.2015. 303016

Buss, D. M (2016). The evolution of desire: Strategies of human mating (Revised and updated edition). New York: Basic Books.

Buss, D. M. (2013). Sexual jealousy. Psihologijske teme, 22(2), 155-182.

Buss, D. M. (2018). Sexual and emotional infidelity: Evolved gender differences in jealousy prove robust and replicable. Perspectives on Psychological Science, 13(2), 155160.

http://doi.org/10.1177/1745691617 698225

Buss, D. M., Larsen, R. J., Westen, D., \& Semmelroth, J. (2001). Sex differences in jealousy: Evolution, physiology and psychology. Emotions In Social Psychology. Essential Readings, 143-149.

Chaudhary, N., Al-Shawaf, L., \& Buss, D. M. (2018). Mate competition in Pakistan: Mate value, mate retention, and competitor derogation. Personality and Individual Differences, 130, 141146. http://doi.org/10.1016/j.paid.2018. 04.007 
Connell, R. W. (1987). Gender and power Stanford. CA: Stanford Univesity.

DelPriore, D.J., Hill, S.E., \& Buss, D.M. (2012). Envy: Functional specificity and sex differentiated design features. Personality and Individual Differences, 53, 317322.

http://doi.org/10.1016/j.paid.2012. 03.029

Donovan, S., \& Emmers-Sommer, T. M. (2012). Attachment style and gender as predictors of communicative responses to infidelity. Marriage \& family review, 48(2), 125-149. http://doi.org/10.1080/01494929.2 011.626670

Duntley, J.D., \& Buss, D.M. (2012). The evolution of stalking. Sex Roles, 66, 311-327.

Edlund, J. E., \& Sagarin, B. J. (2017). Sex differences in jealousy: A 25-year retrospective. Advances in Experimental Social Psychology, 55, 259-302. http://doi.org/10.1016/bs.aesp.2016 .10 .004

Fisher, M. (Ed.) (2017). The oxford handbook of women and competition. Oxford University Press.

Geary, D. C. (2010). Male, female: The evolution of human sex differences. Washington, DC: American Psychological Association. http://doi.org/10.1037/12072-000

Hahm, H. C., Lee, J., Rough, K., \& Strathdee, S. A. (2012). Gender power control, sexual experiences, safer sex practices, and potential HIV risk behaviors among young Asian-American women. AIDS and Behavior, 16(1), 179-188. http://doi.org/10.1007/s10461-0119885-2

Kemer, G., Bulgan, G., \& Yıldız, E. Ç. (2016). Gender differences, infidelity, dyadic trust, and jealousy among married Turkish individuals.

Current

Psychology, 35(3), 335-343. http://doi.org/10.1007/s12144-0149298-2

Mathes, E. W., \& Severa, N. (1981). Jealousy, romantic love, and liking: Theoretical considerations and preliminary scale development. Psychological reports, 49(1), 23-31. http://doi.org/10.2466/pr0.1981.49. 1.23

Pietrzak, R., Laird, J. D., Stevens, D. A., \& Thompson, N.S. (2002). Sex differences in human jealousy: a coordinated study of forced-choice, continuous rating-scale, and physiological responses on the same subjects. Evolution and Human Behavior, 23, 83-94. http://doi.org/10.1016/S10905138(01)00078-2

Pollet, T. V., \& Saxton, T. K. (2020). Jealousy as a Function of Rival Characteristics: Two large replication studies and metaanalyses support gender differences in reactions to rival attractiveness but not dominance. Personality and Social Psychology Bulletin, 00 (0), 1-16.

http://doi.org/10.1177/0146167220 904512

Sagarin, B.J., Martin, A.L., Coutinho, S.A., Edlund, J.E., Patel, L., Skowronski, J.J.,

Zengel, B. (2012). Sex differences in jealousy: A meta-analytic examination. Evolution and Human Behavior, 33, 595-614. http://doi.org/10.1016/j.evolhumbe hav.2012.02.006

Sheets, V. L., \& Wolfe, M. D. (2001). Sexual jealousy in heterosexuals, lesbians, and gays. Sex roles, 44(56), 255-276. http://doi.org/10.1023/A:10109966 31863

Soper, D. S. (2019). A-priori sample size calculator multiple hierarchical 
regression models. http://www. danielsoper. com/statcalc3/calc. aspx.

Valentova, J. V., de Moraes, A. C., \& Varella, M. A. C. (2020). Gender, sexual orientation and type of relationship influence individual differences in jealousy: A large Brazilian sample. Personality and Individual Differences, 157, 109805.

http://doi.org/10.1016/j.paid.2019. 109805

von Hippel, W., \& Buss, D. M. (2017). Do ideologically driven scientific agendas impede the understanding and acceptance of evolutionary principles in social psychology? In L. Jussim \& J. Crawford (Eds.), Political bias in psychology (pp. 725). Cambridge, England: Cambridge University Press.

Yeniceri, Z., \& Kökdemir, D. (2006). University Students' perceptions of, and Explanations for, Infidelity: The Development of the Infidelity Questionnaire (INFQ). Social Behavior \& Personality: an international journal, 34(6).639-50. 